\title{
ИСПОЛЬЗОВАНИЕ БОЛЬШИХ ДАННЫХ НА ПРИМЕРЕ ПРОДУКТОВ КОМПАНИИ 1С
}

\author{
И.т.н. Бакунова О. М. \\ М.т.н. Бакунов А. М. \\ К.т.н. Образцова О. Н. \\ М.т.н. Воробей В. $A$. \\ Республика Беларусь, г. Минск, Институт информачионных технологий \\ Белорусского государственного университета информатики и радиоэлектроники
}

\section{DOI: https://doi.org/10.31435/rsglobal_wos/31102019/6738}

\section{ARTICLE INFO}

Received: 18 August 2019

Accepted: 16 October 2019

Published: 31 October 2019

\section{ABSTRACT}

Now in the market of software products various information systems intended for the solution of tasks of accounting, tax, warehouse accounting and trade activity of the enterprise are offered.

\section{KEYWORDS}

modern technologies, software

products, information systems, $1 \mathrm{C}$.

Citation: Бакунова О. М., Бакунов А. М., Образцова О. Н., Воробей В. А. (2019) Ispol'zovanie Bol'shih Dannyh na Primere Produktov Kompanii 1C. International Academy Journal Web of Scholar. 10(40), doi: 10.31435/rsglobal_wos/31102019/6738

Copyright: (C) 2019 Бакунова О. М., Бакунов А. М., Образцова О. Н., Воробей В. А. This is an open-access article distributed under the terms of the Creative Commons Attribution License (CC BY). The use, distribution or reproduction in other forums is permitted, provided the original author(s) or licensor are credited and that the original publication in this journal is cited, in accordance with accepted academic practice. No use, distribution or reproduction is permitted which does not comply with these terms.

Введение. На сегодняшний день рост количества поступающей информации предопределил развитие технологий обработки большого количества данных BIGDATA. Обработка больших данных требует создания специального программного обеспечения и решения вопроса структурирования неструктурированных данных.

Компании в условиях действующего законодательства и современного рынка обязаны тратить сотни миллионов на оборудование, системы хранения и обработки больших объемов данных.

Сегодняшний рынок аналитики больших данных сильно отличается от отрасли, существовавшей несколько лет назад. Грядущее десятилетие ознаменуется переменами и инновациями в каждом сегменте этой глобальной индустрии.

Аналитическая группа SiliconAngle в своем отчете Wikibon прогнозирует, что общий рынок аналитики больших данных будет расти на $11 \%$ в год, и к 2027 году достигнет \$103 млрд. во всем мире. Большая часть роста рынка в последующие годы будет благодаря анализу больших данных в интернете вещей (IоT), мобильности и других случаях использования периферийных вычислений.

Индустрия больших данных объединяет трех основных поставщиков общедоступных облаков - AmazonWebServices, Microsoft Azure и GoogleCloudPlatform. Большинство поставщиков программного обеспечения создают решения, которые работают во всех индустриях. Эти и другие поставщики общедоступных облаков больших данных, включая, IBM и Oracle, предлагают управляемые пакеты данных IaaS и PaaS, в которые клиентам и партнерам рекомендуется разрабатывать новые приложения и в которые они переносят устаревшие приложения. Как следствие, поставщики PureDataplatform/NoSQL кажутся не такими актуальными, теряют свою значимость в большом пространстве данных, в котором все больше доминируют диверсифицированные поставщики публичных облаков.[1] 
На основании выше сказанного, можно сделать вывод, что наиболее перспективной является связка технологий облачных сервисов и BigData. Это обоснованно тем, что не все компании могут позволить себе отводить целые этажи под сервера хранения для данных, в то время как облачные сервисы уже сейчас позволяют развернуть практически любое программное обеспечение и не требуют таких финансовых трат. Консолидация данных на открытых серверах позволит более полно и корректно анализировать и работать с этими данными, в случае совместной работы нескольких предприятий. Однако все эти нововведения требуют как адаптации существующего программного обеспечение так и разработки нового ПО с более активным применением технологий ИИ и машинного обучения для обработки больших объемов информации которые помогут человеку не потеряться в огромном потоке информации и вовремя принимать необходимые решения по тем или иным задачам.

Реализация технологий Big Data в области инновационной экономики позволяет специалистам по бухгалтерскому учету более тщательно изучить и выбрать эффективный продукт для конкретной экономической задачи. Благодаря анализу информации, специалистам становится удобнее вести бухгалтерский учет от УСН до крупных холдинговых компаний в рамках одной организации. Как результат - упрощение работы бухгалтера.

Понимание пользовательских запросов и таргетинг - одна из самых больших и максимально освещенных широкой публике областей применения инструментов Big Data. Большие Данные помогают анализировать клиентские привычки, чтобы в дальнейшем лучше понимать запросы потребителей.

Новая методика позволила взглянуть на возможности бухгалтерского учета с другой стороны, что привело к открытию новых возможностей. Анализ данных - это инструмент к получению компаниями полного представления относительно ключевых аспектов их бизнеса. Увеличение доходов, снижение затрат и сокращение оборотного капитала являются теми тремя задачами, которые современный бизнес пытается решить с помощью аналитических инструментов.

Например, в настоящее время все большую популярность набирает платформа программирования $1 \mathrm{C}$. Компания «1С» предлагает использовать облачные сервисы по ведению бухгалтерии, встраивает облачные решения в конфигуратор, использует облачные архивы, сервисы доступа к функциональным моделям ERP-систем и многое другое.

B основе ERP-систем лежит принцип создания единого хранилища (репозитория) данных, содержащего всю корпоративную бизнес-информацию: плановую и финансовую информацию, производственные данные, данные по персоналу и др. Наличие единого корпоративного репозитория устраняет необходимость в передаче данных от одной системы к другой (например, от производственной системы к финансовой или к кадровой), а также обеспечивает одновременную доступность информации для любого числа сотрудников предприятия, обладающих соответствующими полномочиями.

ERP-системы предназначены для управления всей финансовой и хозяйственной деятельностью предприятия. Они используются для оперативного предоставления руководству предприятия информации, необходимой для принятия управленческих решений, а также для создания инфраструктуры электронного обмена данными предприятия с поставщиками и потребителями. ERP-системы позволяют использовать одну интегрированную программу вместо нескольких разрозненных. Единая система может управлять обработкой, логистикой, дистрибуцией, запасами, доставкой, выставлением счетов-фактур и бухгалтерским учетом.

Помимо необходимости сбора данных для компании, обработка поступающей информации дает возможность предоставлять клиентам индивидуализированный набор товаров, собранных исходя из предпочтений и возможностей. Ориентирование подобным образом обеспечивает рост конверсии до $37 \%$, учитывая относительную простоту настройки подобного модуля для владельца бизнеса, а также повышенного интереса со стороны клиента можно прийти к выводу о практической пользе использования технологий Big Data для покупателей.

Выводы. B маркетинге инструменты Big Data позволяют выявить, продвижение каких идей на том или ином этапе цикла продаж является наиболее эффективным. С помощью анализа данных определяется, как инвестиции способны улучшить систему управления взаимоотношениями с клиентами, какую стратегию следует выбрать для повышения коэффициента конверсии и как оптимизировать жизненный цикл клиента. 


\section{ЛИТЕРАТУРА}

1. Bigdata analytics: the cloud-fueled shift now underway Режим доступа: https://www.itnews.com/article/3261145/big-data/big-data-analytics-the-cloud-fueled-shift-now-under-way.html

2. Бакунов А.М., Бакунова О.М., Калитеня И.Л., Образцова О.Н. Применение ИКТ в образовательном процессе специальности «Программное обеспечение информационных технологий» специализации «Программное обеспечение обработки экономической и деловой информации» / Подготовка специалиста профессионала в различных видах деятельности : [электронный ресурс] : материалы Республиканской научно-практической конференции с международным участием, Гомель, 23-24 ноября 2017 г. - Гомель : Гомельский областной институт развития образования, 2017. - С. 43 - 46.

3. Бакунова О. М., Бакунов А. М. Программные продукты, предназначенные для решения задач современной экономики на платформе 1с: предприятие. International academy journal Web of Scholar 6 Vol.1, - Warsaw, Poland, 2019

4. Фирма «1С»1C: Предприятие 8.2. Практическое пособие разработчика. Примеры и типовые приемы. - Москва, 2013 - 298 с

5. Фирма «1С»1С: Предприятие 8.3 Версия для обучения программированию - Москва, 2015 - 700 с.

6. Бакунова О. М., Калитеня И. Л., Бакунов А. М., Малиновская Т. И. Подготовка ІТ специалистов уо бгуир в области 1C. International Journal of Innovative Technologies in Economy 1(13) February 2018. C 80-82.

7. Бакунова О. М., Калитеня И. Л., Образцова О. Н., Хмелевская А. Л., Биркос В. А., Коляго В. В., Бурак Д. И., Акулич А. Д., Пазушко В. В. Особенности компетентной подготовки специалистов 1С. International Journal of Innovative Technologies in Economy Warsaw, Poland, 6(18), Vol. 1, July 2018. C 12-14 